\title{
Clinical efficacy of autogenous vertebrae-filled polyetheretherketone cage in anterior cervical discectomy and fusion with instrumentation
}

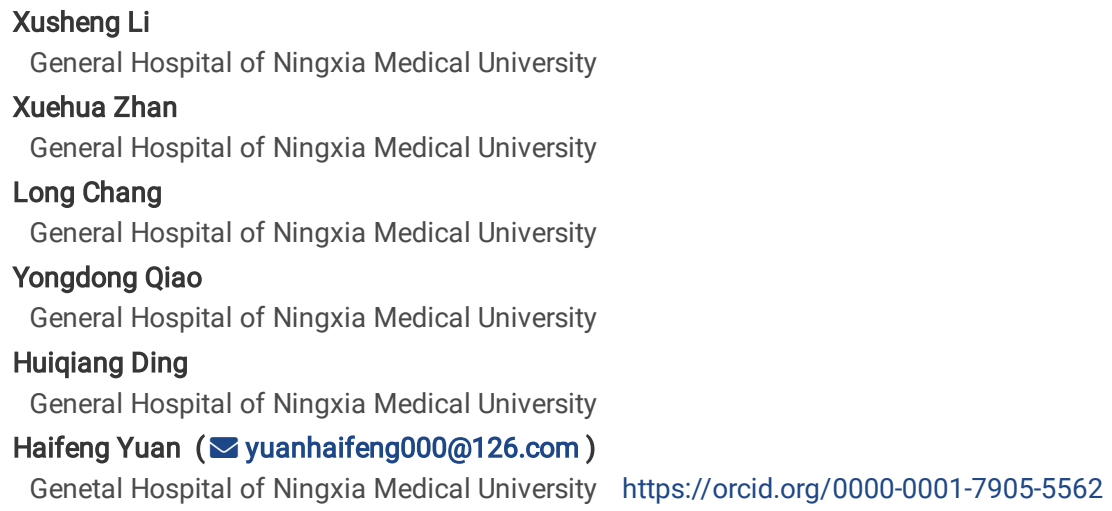

Research article

Keywords: Autologous, Vertebrae, lliac, PEEK, ACDFI

Posted Date: April 13th, 2021

DOI: https://doi.org/10.21203/rs.3.rs-411395/v1

License: () (7) This work is licensed under a Creative Commons Attribution 4.0 International License. Read Full License 


\section{Abstract}

Background. Anterior cervical discectomy and fusion with instrumentation (ACDFI) have been widely used in the treatment of the degenerative disease or traumatic instability of the cervical spine. This study aimed to investigate the clinical efficacy of the autologous vertebral-filled polyetheretherketone (PEEK) cage in anterior cervical discectomy and fusion with instrumentation (ACDFI).

Material and Methods. The clinical data of 368 patients who received ACDFI from September 2015 to September 2020 were retrospectively analyzed. According to the material that filled PEEK cage during the surgery, the patients were divided into two groups, the autologous vertebrate group ( $\mathrm{n}=185$ ) and the autologous iliac group $(n=183)$. The operative time, operative blood loss, postoperative complications in two groups were recorded and analyzed. The bone graft fusion and postoperative functional outcomes, including scores of modified Japanese Orthopedic Association score (mJOA), Neck Disability Index (NDI), and visual analog scale (VAS) were compared.

Results. Patients were followed-up for $14.04 \pm 0.98$ months. At a 6-months follow-up, the rate of spinal fusion was $96.29 \%$ (178/185) in the vertebral group and $95.94 \%(176 / 183)$ in the iliac group, there was no statistically significant difference between the two groups (P>0.05). The postoperative VAS, mJOA, and NDI scores were not significantly different between two groups during the follow-up ( $P>0.05)$. The operative time and blood loss in the vertebral group were significantly less than that of the iliac group $(P<0.01)$. In the iliac group, all patients suffered pain in the iliac donor site, 65 patients suffered numbness, 12 patients had fat liquefaction in donor incision, while all patients in the vertebral group had no postoperative complications.

Conclusion. The autologous vertebrae-filled PEEK cage can achieve the same clinical outcome as the autologous iliac, but the autologous vertebrae filled PEEK cage have the advantage of shorter operative time, less intraoperative blood loss, and postoperative complications.

\section{Introduction}

Anterior cervical discectomy and fusion with instrumentation (ACDFI) have been widely used in the treatment of degenerative disease or traumatic instability of the cervical spine[1, 2]. In the past, the autologous iliac crest (AIC) was considered to be the best material for intervertebral support and bone graft fusion, however, the absorption and displacement of the grafted bone is one of the long-term complications.[3] The intervertebral polyetheretherketone (PEEK) cage is a material with excellent biocompatibility, it could not only immobilize the unstable motion segment but also maintain the height of intervertebral effectively. [4] Currently, Autologous iliac bone is the most commonly used bone graft material for filling PEEK cages,[5] however, it requires an additional surgical incision, which may lead to complications in the donor site. Autogenous vertebrae without osteophytes collected during decompression can be an ideal material for filling intervertebral cage, however, its long-term efficacy still needs to be confirmed. This study aimed to investigate the clinical efficacy of autologous vertebrae filled PEEK cage in ACDFI, thus exploring the feasibility of the autologous vertebrae bone as the bone graft fusion material.

\section{Materials And Methods}

The inclusion criteria were as follows: (1) Patients with single-segment cervical disc herniation who failed in conservative treatment for more than 3 months, without spinal stenosis or instability of other segments; (2) Patients with a degenerative disease which caused a single segmental cervical spondylotic radiculopathy; (3) Patients suffered from single-segment intervertebral instability caused by trauma, along with abnormal signals of the spinal cord in MRI, with or without neurological symptoms; (4) Patients with cervical hyperextension injury and MRI showed an interruption of the anterior longitudinal ligament and a mixed-signal change in the intervertebral disc. Patients were excluded if they had: severe osteoporosis, a tumor in the cervical spine, a history of cervical surgery, acute spinal infections, and systemic infections.

The clinical data of 368 patients were retrospectively reviewed. According to the bone graft materials used in filling the PEEK cage, the patients were divided into two groups, autogenous vertebrae-filled PEEK cage group $(n=185)$ and autologous iliac bone-filled PEEK cage group ( $n=183)$. All patients received single-segment anterior cervical discectomy and decompression with instrumentation (ACDFI), the interverbal space was supported by PEEK Cage filled with bone graft and fixed by instrumentation. This study was approved by the ethics committee of our hospital. The general information of patients was shown in Table $₫$.

All of the surgical procedures were performed by the same surgeon. After general anesthesia, patients were placed in a supine position. A standard right-sided ACDFI was performed through a transverse incision. Cutting the platysma horizontally and revealed the pre-vertebral fascia after blunt separation along the vascular sheath and the visceral sheath, the vertebral body, and intervertebral disc were exposed carefully. The segment of the lesion was confirmed by intraoperative fluoroscopy, and discectomies were performed. Osteophytes and soft tissues around the intervertebral space were removed for the fixation of the titanium plate and the preparation of bone graft materials. The intervertebral space was opened by using a Casper disc expander, and then the upper and lower endplate annulus fibrosus and cartilage endplate tissue were scraped. The posterior longitudinal ligament was cut, ensure that the dural and intervertebral foramen were adequately decompressed, then the cage and anterior locking plate was placed.

Preparation of PEEK Cage-filled bone graft material. Autologous vertebral group: after clearing the anterior cervical soft tissue, the osteophytes of the anterior and posterior margin of the vertebral body (the red area in Fig. 1) were all removed. The normal vertebral bone tissues in the anterior and posterior margins of the upper and lower vertebral bodies were obtained, including part of the cancellous bone (green area in Fig. 1) without osteophytes. In the autologous iliac group, a right anterior superior iliac incision was made, the cancellous iliac bone was scraped with a spoon after cortical fenestration.

Patients were allowed to attend an off-bed exercise on the first day after the operation, the drainage was removed when the drainage was less than $5 \mathrm{ml}$, and the dressings of the surgical site were changed regularly to observe the healing of the incisions. Postoperative complications in the donor site or cervical 
The clinical and radiographic evaluations were performed preoperatively and at 6- and 12- months after surgery. The operative time, intraoperative blood loss, postoperative hospital stays, and postoperative complications were recorded. The VAS score was used to identify the pain level of the neck and upper arms, and the mJOA score and NDI score were used to evaluate the neurological function. Radiological outcomes including bone fusion rate, lordosis of the cervical spine, and subsidence of cage were assessed by radiographs and CT scans. The standard of radiological bone graft fusion[6] was as follows: (1) There was no clear shadow between Cage and endplate, and trabecular bone grows through the interface; (2) There was a bone bridge between the upper and lower endplates, whether the bone bridge was located inside or outside the Cage; (3) Translucent bands were not seen in the fusion cage or intervertebral space. The radiological evaluation was determined independently by two orthopedic surgeons who were blinded to the design of the research (Fig. 2).

SPSS 22.0 software (IBM, New York, USA) was used for statistical analysis. A comparison between the groups was performed by $t$-test, one-way analysis of variance (ANOVA), or chi-square test. Data were expressed as mean \pm standard deviation $(\bar{x} \pm s)$ or percentages $(\%)$. $P<0.05$ was considered to be statistically significant.

\section{Results}

There was no statistically significant difference between the two groups in gender, age, the segment of disease, operative segments, pre-operative VAS score, mJOA score, and NDI score $(P>0.05)$. The operative time in Group A was significantly shorter than that of Group B $(P<0.01)$. The blood loss in group A was significantly fewer than that of group $\mathrm{B}(P<0.01)$. There was no significant difference in postoperative hospitalization days between the two groups (Table $\mathbb{\nabla})$. No postoperative complications occurred in group $A$, while all patients in group B suffered pain in the iliac donor region. 65 patients in group $B$ suffered numbness in the skin around the donor region, and fat liquefaction in the iliac donor incision occurred in 12 patients.

After surgery, patients reported significant relief of pain and gradually release of symptoms, and they were followed-up at 6-and 12- months after surgery. The VAS score, mJOA score, and NDI score significantly improved at 6 - and 12-months follow-up after surgery compared to preoperative data $(P<0.01)$. There were no significant differences in VAS scores, mJOA scores, and NDI scores between the two groups at one year and two years after surgery $(P>0.05)$ (Table 凶).

At a 6-month follow-up, the fusion rate in group A and group B was 77.14\% (143/185) and 75.76\% (139/183), respectively, and there was no significant difference between the two groups $(P>0.05)$. The fusion rate in the two groups at 12-month follow-up was $94.29 \%(174 / 185)$ and $93.94 \%(172 / 183)$, respectively, and there was no significant difference $(P>0.05)$.

\section{Discussion}

Since anterior cervical discectomy and fusion with instrumentation (ACDFI) was first applied, it was considered a standard surgical procedure for degenerative and traumatic cervical diseases. However, clinical efficacy is closely related to the efficacy of intraoperative decompression and postoperative intervertebral fusion.[7] To achieve satisfying intervertebral fusion, it is crucial to select a suitable interbody fusion material. The commonly used materials mainly include autologous iliac bone, allogeneic bone, and synthetic materials. The autologous iliac bone is the material with the highest bone fusion rate, but additional incision is required and donor site complications cannot be avoided; the allogeneic bone has high expenses and incidence of bone graft-related complications. A cage filled with allogeneic bone or synthetic materials could avoid those disadvantages, but the bone fusion rate and the reliability are controversial.[8, 9]

In 2000, a prospective, randomized, multicenter clinical study focusing on the use of the cervical Spine Cage was published on the Spine, the intervertebral cage was then widely used in ACDFI.[10] The innovation and improvement of the intervertebral cage greatly enhanced the development of ACDFI, The type of intervertebral cage included stainless-steel cage, titanium alloy cage, and PEEK Cage.[11] PEEK cage has good biomechanical properties, and its elastic modulus is close to the vertebral body, the height of intervertebral space can also be maintained effectively. Meanwhile, PEEK Cage has the advantages of Xray penetrability, and its hollow design can be filled with bone graft material to improve the fusion rate.[12]A lot of research articles on PEEK Cage were published and it was reported to achieve promising results in ACDFI, which is now the most popular intervertebral fusion material.[13]

The ideal PEEK Cage-filled bone grafting materials should be excellent in conductivity, induction, and osteogenesis of bone, moreover, the materials should be convenient and cheap.[14] Autologous bone is currently recognized as an ideal bone graft material. It has been reported that the intervertebral fusion rate of single-segment ACDFI using cortical iliac bone-filled PEEK Cage was over 95\%, and the improvement rate of neurological symptoms was close to 80\%.[15, 16] However, an additional surgical incision is needed, postoperative complications such as pain, bleeding, infection, disruption of femoral lateral cutaneous nerve and ilioinguinal nerve, and fracture of iliac frequently occurred.[17, 18] It was reported that the incidence of donor-site related complications ranged from 9.4$49 \% .[16,18]$ The clinical applications of allogeneic bone, artificial bone, and other materials are limited due to their high price and low fusion rate.

The osteophytes extracted from local bites during anterior surgical decompression can be used as filling materials, but their clinical efficacy is limited. It was difficult to completely remove the soft tissue and fibrous tissue attached to the surface of osteophytes, the effect of bone graft fusion would be affected by the low levels of osteoblasts. Min et al conducted a study to compare the proliferation and ossification of bone marrow stem cells in autogenous vertebrae and autologous iliac bone, it was found that the proliferation and ossification of bone marrow stem cells were similar.[19] In this study, we used autogenous vertebrae as the bone graft material for the filling of the PEEK Cage. As is known from the anatomy of the cervical vertebral body, the lower endplate of the cervical vertebra is concave, while the anterior and lower margin of the vertebral body is lip-shaped. The degeneration of the intervertebral disc and the proliferation of osteophytes in the anterior margin of the vertebral body results in obvious narrowing of the vertebral space. To achieve sufficient decompression in the anterior and posterior intervertebral space and the vertebral canal, the osteophyte and the labial structure of the vertebral body were usually removed intraoperatively to expand the operative field. The anterior and posterior vertebrae of the upper and lower vertebral bodies are removed without causinc sianificant damane tn the unner and lower endplates, and the preparation of bone graft beds would also not be affected.

Loading [MathJax]/jax/output/CommonHTML/fonts/TeX/fontdata.js

Page 3/6 
The clinical benefits of autogenous vertebrae mainly include: (1) No additional iliac bone extraction was performed during the operation, the operative time was significantly shortened; (2) The intraoperative blood loss was significantly fewer because no additional incision was needed; (3) Postoperative complications on donor site can be fully avoided; (4) The vertebral extracted from the body is convenient and cheap compared to the allogeneic bone; (5) At the 12-months follow-up, the bone fusion rate and functional outcomes were excellent, indicating that the autologous vertebrate filled PEEK Cage can achieve a satisfying clinical outcome.

\section{Conclusion}

The application of autologous vertebral filled with PEEK Cage could achieve satisfactory bone graft fusion and functional outcomes, and it is convenient and cheap, which may be an ideal bone graft material in ACDFI. We acknowledge that this study has some limitations, it is a retrospective study with a short time of follow-up. A prospective, randomly controlled and long-term followed-up study should be performed in the future study.

\section{Abbreviations}

PEEK: polyetheretherketone; ACDFI: anterior cervical discectomy and fusion with instrumentation

\section{Declarations}

\section{Authors contributions}

Xusheng Li and Xuehua Zhan contributed to the study conception and design. Material preparation, data collection, and analysis were performed by Long Chang, Yongdong Qiao, Huiqiang Ding, and Haifeng Yuan. The first draft of the manuscript was written by Xusheng Li and all authors commented on previous versions of the manuscript. All authors read and approved the final manuscript.

\section{Funding}

This study was funded by The National Natural Science Foundation of China (81760231).

\section{Availability of data and material}

All data generated or analyzed during this study are included in this published article [and its supplementary information files].

\section{Declarations}

\section{Ethical approval and consent to participate}

This study was conducted in accordance with the ethical guidelines of the Declaration of Helsinki. This retrospective study was approved by the General Hospital of Ningxia Medical University. Informed consent was obtained from all patients for this study, all patients agreed to participate in the study.

\section{Consent for publication}

All patients agreed to have their data published.

\section{Competing interests}

The authors declare that there is no conflict of competing financial and non-financial interests.

\section{References}

1. Kim LH, D'souza M, Ho AL, Pendharkar AV, Sussman ES, Rezaii P, et al. Anterior Techniques in Managing Cervical Disc Disease. Cureus. $2018 ; 10(8)$ :e3146. https://doi.org/10.7759/cureus.3146.

2. Zou S, Gao J, Xu B, Lu X, Han Y, Meng H. Anterior cervical discectomy and fusion (ACDF) versus cervical disc arthroplasty (CDA) for two contiguous levels cervical disc degenerative disease: a meta-analysis of randomized controlled trials. Eur Spine J. 2017;26(4):985-97. https://doi.org/10.1007/s00586-0164655-5.

3. Kapetanakis S, Thomaidis T, Charitoudis G, Pavlidis P, Theodosiadis P, Gkasdaris G. Single anterior cervical discectomy and fusion (ACDF) using selflocking stand-alone polyetheretherketone (PEEK) cage: evaluation of pain and health-related quality of life. J Spine Surg. 2017;3(3):312-22. https://doi.org/10.21037/jss.2017.06.21.

4. Knaus J, Schaffarczyk D, Cölfen H. On the Future Design of Bio-Inspired Polyetheretherketone Dental Implants. Macromol Biosci. 2020;20(1):e1900239. https://doi.org/10.1002/mabi.201900239.

5. Pirkle S, Kaskovich S, Cook DJ, Ho A, Shi LL, Lee MJ. Cages in ACDF are Associated With a Higher Nonunion Rate Than Allograft: A Stratified Comparative Analysis of 6130 Patients. Spine (Phila Pa 1976). 2019;44(6):384-88. https://doi.org/10.1097/brs.0000000000002854.

6. Park DK, Rhee JM, Kim SS, Enyo Y, Yoshiok K. Do CT scans overestimate the fusion rate after anterior cervical discectomy and fusion? J Spinal Disord Tech. 2015;28(2):41-6. https://doi.org/10.1097/BSD.0b013e31829a37ac. 
7. Broekema AE, Kuijlen JM, Lesman-Leegte GA, Bartels RH, Van Asselt AD, Vroomen PC, et al. Study protocol for a randomised controlled multicentre study: the Foraminotomy ACDF Cost-Effectiveness Trial (FACET) in patients with cervical radiculopathy 2017;7(1):e012829. https://doi.org/10.1136/bmjopen2016-012829.

8. Buser Z, Brodke DS, Youssef JA, Meisel HJ, Myhre SL, Hashimoto R, et al. Synthetic bone graft versus autograft or allograft for spinal fusion: a systematic review. J Neurosurg Spine. 2016;25(4):509-16. https://doi.org/10.3171/2016.1.Spine151005.

9. Shao MH, Zhang F, Yin J, Xu HC, Lyu FZ. Titanium cages versus autogenous iliac crest bone grafts in anterior cervical discectomy and fusion treatment of patients with cervical degenerative diseases: a systematic review and meta-analysis. Curr Med Res Opin. 2017;33(5):803-11.

https://doi.org/10.1080/03007995.2017.1284050.

10. Hacker RJ, Cauthen JC, Gilbert TJ, Griffith SL. A prospective randomized multicenter clinical evaluation of an anterior cervical fusion cage. Spine (Phila Pa 1976). 2000;25(20):2646-54. discussion 55.

11. Omeis I, Demattia JA, Hillard VH, Murali R, Das K. History of instrumentation for stabilization of the subaxial cervical spine. Neurosurg Focus. 2004;16(1):E10.

12. Farrokhi MR, Nikoo Z, Gholami M, Hosseini K. Comparison Between Acrylic Cage and Polyetheretherketone (PEEK) Cage in Single-level Anterior Cervical Discectomy and Fusion: A Randomized Clinical Trial. Clin Spine Surg. 2017;30(1):38-46. https://doi.org/10.1097/bsd.0000000000000251.

13. Chen Y, Lü G, Wang B, Li L, Kuang L. A comparison of anterior cervical discectomy and fusion (ACDF) using self-locking stand-alone polyetheretherketone (PEEK) cage with ACDF using cage and plate in the treatment of three-level cervical degenerative spondylopathy: a retrospective study with 2-year followup. Eur Spine J. 2016;25(7):2255-62. https://doi.org/10.1007/s00586-016-4391-x.

14. Park HW, Lee JK, Moon SJ, Seo SK, Lee JH, Kim SH. The efficacy of the synthetic interbody cage and Grafton for anterior cervical fusion. Spine (Phila Pa 1976). 2009;34(17):E591-5. https://doi.org/10.1097/BRS.0b013e3181ab8b9a.

15. Buttermann GR. Anterior Cervical Discectomy and Fusion Outcomes over 10 Years: A Prospective Study. Spine (Phila Pa 1976). 2018;43(3):207-14. https://doi.org/10.1097/brs.0000000000002273.

16. Burneikiene S, Nelson EL, Mason A, Rajpal S, Villavicencio AT. The duration of symptoms and clinical outcomes in patients undergoing anterior cervical discectomy and fusion for degenerative disc disease and radiculopathy. Spine J. 2015;15(3):427-32. https://doi.org/10.1016/j.spinee.2014.09.017.

17. Armaghani SJ, Even JL, Zern EK, Braly BA, Kang JD, Devin CJ. The Evaluation of Donor Site Pain After Harvest of Tricortical Anterior Iliac Crest Bone Graft for Spinal Surgery: A Prospective Study. Spine (Phila Pa 1976). 2016;41(4):E191-6. https://doi.org/10.1097/brs.0000000000001201.

18. Silber JS, Anderson DG, Daffner SD, Brislin BT, Leland JM, Hilibrand AS, et al. Donor site morbidity after anterior iliac crest bone harvest for single-level anterior cervical discectomy and fusion. Spine (Phila Pa 1976). 2003;28(2):134-9. https://doi.org/10.1097/01.brs.0000041587.55176.67.

19. Min WK, Bae JS, Park BC, Jeon IH, Jin HK, Son MJ, et al. Proliferation and osteoblastic differentiation of bone marrow stem cells: comparison of vertebral body and iliac crest 2010;19(10):1753-60.

\section{Tables}

Table 1 General information of patients in two groups

\begin{tabular}{|c|c|c|c|c|c|c|c|c|c|c|}
\hline \multirow[t]{2}{*}{ Groups } & \multirow[t]{2}{*}{$\mathrm{n}$} & \multirow[t]{2}{*}{ Age } & \multicolumn{2}{|c|}{ Gender } & \multicolumn{4}{|c|}{ Segment } & \multicolumn{2}{|c|}{ Diseases } \\
\hline & & & Male & Femal & C3-4 & C4-5 & C5-6 & C6-7 & Degeneration & Trauma \\
\hline Autologous vertebrate & 185 & $53.1 \pm 5.01$ & 95 & 90 & 29 & 58 & 64 & 34 & 137 & 48 \\
\hline Autologous iliac & 183 & $52.9 \pm 4.87$ & 90 & 93 & 26 & 56 & 66 & 35 & 141 & 42 \\
\hline
\end{tabular}

Table 2 Comparison operative data and postoperative complications between the two groups

\begin{tabular}{lllll}
\hline Groups & $\mathrm{n}$ & Operative time & Blood loss & Postoperative hospital stay \\
\hline Autologous vertebrate & 185 & $94.45 \pm 10.87$ & $34.24 \pm 8.21$ & $6.36 \pm 0.74$ \\
Autologous iliac & 183 & $106.75 \pm 16.13$ & $62.73 \pm 12.19$ & $6.67 \pm 1.14$ \\
$t$ & -3.658 & -14.41 & -1.67 \\
$P$ & 0.001 & 0.000 & 0.11 \\
\hline
\end{tabular}

\section{Table 3 Comparison of function score of the two groups}




\begin{tabular}{|c|c|c|c|c|c|c|c|c|c|c|}
\hline \multirow[t]{2}{*}{ Groups } & \multirow[t]{2}{*}{$\mathrm{n}$} & \multicolumn{3}{|c|}{ VAS } & \multicolumn{3}{|c|}{$\mathrm{mJOA}$} & \multicolumn{3}{|c|}{ NDI } \\
\hline & & Preoperative & 6 months & $\begin{array}{l}12 \\
\text { months }\end{array}$ & Preoperative & 6 months & 12 months & Preoperative & 6 months & $\begin{array}{l}12 \\
\text { months }\end{array}$ \\
\hline $\begin{array}{l}\text { Autologous } \\
\text { vertebrate }\end{array}$ & 185 & $6.09 \pm 0.69$ & $3.12 \pm 0.82$ & $1.82 \pm 0.58$ & $7.30 \pm 1.26$ & $13.97 \pm 0.15$ & $15.23 \pm 1.57$ & $35.33 \pm 1.54$ & $7.27 \pm 0.91$ & $3.40 \pm 1.07$ \\
\hline $\begin{array}{l}\text { Autologous } \\
\text { iliac }\end{array}$ & 183 & $6.00 \pm 0.62$ & $3.36 \pm 0.86$ & $1.97 \pm 0.59$ & $7.63 \pm 1.19$ & $13.70 \pm 0.17$ & $15.07 \pm 1.41$ & $35.23 \pm 1.38$ & $7.33 \pm 1.09$ & $3.67 \pm 1.12$ \\
\hline$t$ & & 0.90 & -1.76 & -1.41 & -1.00 & 1.77 & 0.80 & 0.42 & -0.24 & -1.49 \\
\hline$p$ & & 0.37 & 0.09 & 0.17 & 0.33 & 0.088 & 0.43 & 0.68 & 0.81 & 0.15 \\
\hline
\end{tabular}

\section{Figures}

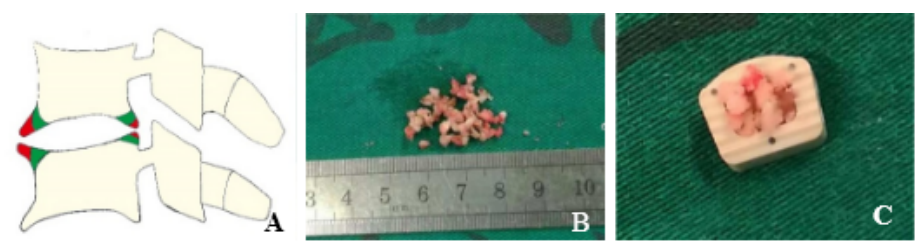

Figure 1

(A) A sketch map of the excision of autologous vertebrae. (B) Autologous vertebrae excised from intervertebral space. (C) A cage filled with autologous vertebrae.
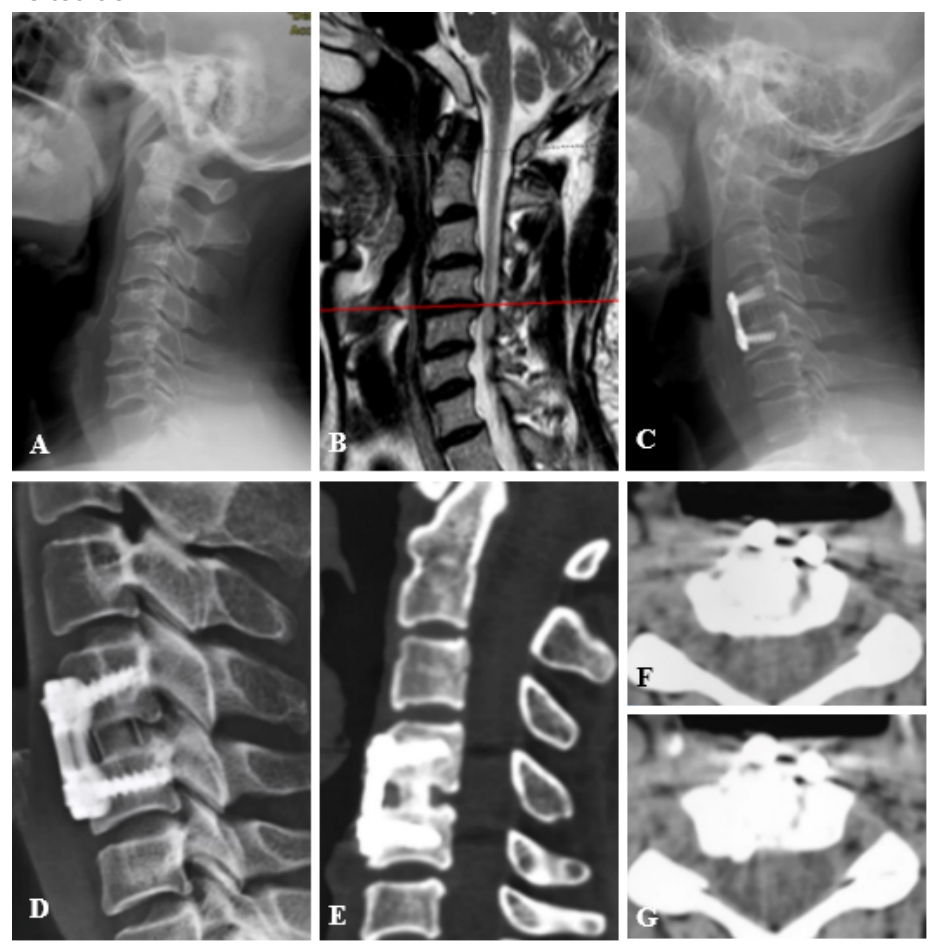

\section{Figure 2}

Patient female, 45 years old, cervical 4-5 disc herniation. The vertebrae space was filled by autologous vertebrae-filled PEEK Cage. (A) A preoperative cervical lateral radiograph (X-ray). (B) Preoperative MRI showed cervical 4-5 disc herniation, compression of the dural sac spinal cord. (C) Postoperative X-ray of the cervical vertebrae. (D) Six months after the operation, an X-ray of the cervical vertebra showed continuous trabecular bone in the cage. (E) The cervical vertebra reconstruction was performed 12 months after surgery. Visible continuous bone bridge formation. (F, G) 12 months after surgery CT axial scan showed good bone graft fusion. 